\title{
Design and Research of Part - time Work Platform for Art Students Based on APP Platform
}

\author{
Yile Sun ${ }^{1}$, Jing Yang ${ }^{2}$ and Jia Zhu ${ }^{2,}{ }^{*}$ \\ 1. College of Education, Hainan Tropical Ocean University, Hainan Sanya 572022, China \\ 2. College of Art and Creativity, Hainan Tropical Ocean University, Hainan Sanya 572022, China \\ zhujia1217@126.com \\ The corresponding author
}

Keywords: Social practice; Part-time; College students entrepreneurship.

\begin{abstract}
In the era of the Internet, demand-oriented Internet business model and value creation is emerging, the current phenomenon of college students work-study is widespread, students often seek part-time channels are scattered, roadside advertising now lacks a focus on students Group of healthy part-time job information exchange platform, the study aims to establish an independent and systematic mode of operation through the website or APP in the form of integration scattered in colleges and universities, as well as social work for students to help the employer more quickly Better find part-time job, in line with the university's talent training strategy.
\end{abstract}

\section{Introduction}

With the increasing development of university education, the number of college students is increasing. Many students are faced with increasing employment pressure after graduation. In the university campus, each student engaged in part-time situation is different, some part-time platform to seize this opportunity for college students to provide a wide range of part-time opportunities, some students in order to reduce the burden on the family, on the part-time platform In addition, there are some students just to create opportunities for their future employment, through the part-time process of continuous exercise their ability to enhance their own ability to do their own work, both to meet the actual needs of life, but also to expand their own vision; And accumulate experience. Regardless of the purpose, part-time platform to a certain extent, to meet the actual needs of college students, and provide them with the exercise of their own, access to income channels. But now, some part-time platform for the services of students under the guise of the students to pay a part of the deposit, but not for them to provide the necessary services, and even the existence of a threat to the interests of the phenomenon, so that they can not pay after the work To obtain the corresponding return, which has a negative impact on their future employment, lost a firm belief. Thus, the feasibility of part-time platform for college students remains to be further studied, the need to consider a wide range of factors, appropriate to take countermeasures to solve the problem.

\section{Analysis on the Feasibility of Part - time Work Platform for College Students}

With the rapid development of education, colleges and universities continued to expand the number of college students more and more, with the emergence of increasingly heavy employment pressure, many college students in order to better find the right job, had to advance into the community, And the earliest contact with the community is engaged in part-time, although this is a lower threshold of employment channels, but many students still stay in the only stage that does not limit.

Part-time platform is built to provide students with access to part-time information channels, if there is no formal part-time platform, students often need to go out through their own way to find, but it is difficult to 
find the right. Some part-time manufacturers will be due to the number of part-time students, but do not want to provide the appropriate duties, but also for the students there is no trust, fear of their part-time belief is not firm, will be half done in the process of halfway, To bring manufacturers to worry about. Some students are afraid of being deceived, if encountered black heart manufacturers, may be hard after the work is not the corresponding remuneration, so that indemnity fees and meals, the road of their own employment have a negative impact.

Because students have less knowledge about jobs and the access to information is limited, it is hard to find the right part-time job for them and have little choice. Students are limited in their energies, and less likely to have enough time and money to look for jobs that are good for themselves. As a result, they are stagnant in part-time jobs and lose a lot of opportunities to help them exercise their abilities.

In summary, part-time platform settings to meet the needs of students to some extent, as long as the students first joined the part-time platform, pay a small part of the fee, you can get ample part-time information, so that by appropriate means To contact the appropriate manufacturers, we can achieve timely communication, and to determine part-time locations, through the formal channels of the platform to protect the information security of both parties and reasonably safeguard their rights and interests. Many companies are happy to recruit college students to do part-time, mostly due to the relatively high personal qualities of college students, recruiting part-time college students can also bring good social reputation and evaluation of hiring units. Still others think that college students are more eager to part-time job, they are less demanding on part-time job types and enterprises, less cognitive ability on job positions, and they are more motivated to work, which is a very good resource for enterprises. In part-time job supply, the business is seldom willing to provide high-tech jobs, because it requires relevant training, part-time college students may not have the appropriate time, or just familiar with the job is about to leave, cannot meet the business needs. In addition, hiring college students part-time for businesses and candidates are faced with unsafe problems in the security, businesses are reluctant to invest too much for short-term workers insurance.

\section{Corresponding Measures for College Students' Part-time Existence Problems}

According to relevant surveys, college students are willing to part-time at the present stage, but due to many factors, college students face many difficulties in the part-time process. Although the establishment of part-time platform can provide many opportunities for college students to work part-time, A variety of negative effects, so that students cannot fully trust the part-time platform and related part-time channels, which is not conducive to solving the part-time demands of college students.

Establish specialized institutions and strengthen education. With the gradual acceleration of social processes and increasing social demand for undergraduates, in the face of increasing numbers of graduates and in order to better meet their employment needs, opportunities should be appropriately created to make them acceptable during college Part-time training ensures that you can lay a good foundation for future development. Therefore, students should be required based on the relevant materials, timely sorting out a variety of problems encountered in the part-time process of college students through campus bulletin boards, campus networks and other channels to promote, so that students can clear part-time process may occur dangerous situations, But also need to regularly address the positive feedback of students valid information, using a variety of ways to constantly improve and update, to ensure timely understanding of college students part-time status. Schools should establish a unified management system, set up the corresponding institutional departments, equipped with specialized tutors to help students solve many problems arising from part-time work. What needs special attention is that tutors should properly analyze different types of problems, Take measures to solve in a timely manner, and after doing a good record for the future application process to provide reference and reference.

Increase technical input and solve problems in time. Facing the numerous changes in the current society, a series of potential risks have emerged along with the premise that a series of advanced measures came into 
being. Network technology belongs to the 21 st century, a fresh product, through the use of JSP, PHP and other effective use of technology, network construction can be achieved. This to some extent, to meet the needs of contemporary college students part-time, through website construction, as long as through simple finger operation, you can easily find many part-time platform, but the hidden authenticity is difficult to distinguish. Many students are confused or even worried about part-time jobs on part-time platforms. Faced with such issues, the government, society and schools should work closely together to establish a special web site agency, and under the premise of school authorization, enterprises and students play an intermediary role to ensure that students will not part-time Deceive in the process.

\section{Part - time job role of college students and framework}

Through the establishment of a third-party platform between enterprises and schools, it can provide students with reliable and safe employment channels so that students can better reach out to the community and achieve the goal of work-study program. And through a comprehensive understanding of third-party platform-related information, to enable students to more timely and clear employer needs, in order to lay a solid foundation for their future employment. At the same time, students gain valuable experience in part-time work and identify future development plans that are positive for their growth. The application of part-time platform can help companies promote part-time information, but also effectively demonstrate corporate culture, which play an active advocacy role.

The emergence of part-time college students is the requirement of the development of the times and also the need of social and economic development. Through the corresponding market investigation and knowledge learning, with the concrete practice of information technology training and strengthening, Innovation awareness has a positive impact. Through the establishment of related platforms, innovative teaching plans can be formed more comprehensively, so it shows great practical significance to the training of college personnel.

The part-time platform for college students is an important channel for providing students with job opportunities and part-time opportunities. In the process of platform construction, the main use of JSP technology to achieve the development of website resources, adhering to the purpose of providing part-time information for college students, covers the hot jobs, Information and resumes and many other internal functions. JSP technology is the application of cross-platform features in traditional web pages, which can better separate the page logic from the web design display, and also supports reusable component design, which makes the development process of web applications easier. In this process, JSP technology reflects the soundness and security of storage processing, and effectively implements the functions of rapid deployment, maintenance and modification.

The traditional part-time platform is easily subject to geographical restrictions resulting in information processing is not timely, so to enterprises and part-time students bring great inconvenience, affecting the normal operation of business and students need part-time. The development of modern science and technology, so that part-time platform is no longer affected by the geographical area, just through the network client, you can easily query the information in time, the choice and release. Businesses can update part-time job vacancies at any time, and release requirements more quickly, and students have the option of actively looking for jobs that fit their needs and meet the real requirements of business growth and student part-time employment.

The most important reason for the development and application of college part-time platform is that the related hardware and software systems are relatively simple to purchase in the mainstream market, and the costs involved are not high. They can also be downloaded directly from the Internet through the Internet. The development cost of the part-time platform for college students is mainly used in the maintenance of the website, so it will not cause excessive economic burden on the development team. The part-time platform 
for college students has a relatively short development cycle, which results in an extremely high price / performance ratio compared with the practical significance and economic benefits.

\section{Summary}

Through the study of the feasibility of part-time platform for college students, this paper clarifies the actual needs of part-time students in today's society. In order to better cater to the changing mode of the times, we use the network technology and the network culture at this stage to provide part-time work for college students through various channels, And the development of enterprises play a good publicity role. Part-time platform is connected to the community, schools and students of the three media, it should have legitimacy, formality, the times and other advantages, through the unique value of innovation for the future employment of college students to help.

\section{Acknowledgement}

This research was financially supported by the 2015 Innovative Entrepreneurship Project of College Students in Hainan Province (No.20150127).

\section{References}

[1] K.Y. Li. An Analysis of the Current Situation of Part - time College Students and the Management Strategy - Taking Ningbo Radio and Television University as an Example [J]. Journal of Ningbo Radio and Television University, 2015, No.1: 73-78.

[2] Y. Zhang, X.L. Wang. Relying on the National One - stop Employment System for College Students to Construct a Part - time Protection Platform for College Students [J]. Law and Society, 2015, No.10: 208-209.

[3] K.J. Pang, M.B. Xiang, X.L. Yin, K. Yang. A Study on the Relationship between Part - time and Learning in College Students - Based on the Analysis of Rongchang Campus in Southwest University [J]. Modern Business Industry, 2015, No.18: 94-95.

[4] Y.J. Cao. An Investigation and Analysis of the Status Quo of College Students' Part - time - Taking Some Universities in Hefei as an Example [J]. Science and education, 2015, No.9: 153-154.

[5] L. Li, Y.L. Wang. A Study on the Protection of College Students' Rights and Interests - Based on the Investigation of Two University Towns [J]. Shanghai enterprises, 2013, No.1: 74 -76. 